\title{
Molecular evidence of autophagy impairment as serum level of ATG13 is elevated in patients with myalgic encephalomyelitis and chronic fatigue syndrome: two independent case-control studies
}

Avik Roy ( $\sim$ aroy@simmaron.com )

Simmaron Research Inc https://orcid.org/0000-0003-0523-8504

Carl Gunnar Gottschalk

Simmaron Research INC.

Daniel Peterson

Sierra Internal Medicine

Konstance Knox

Coppe healthcare Solutions

Marco Maynard

Simmaron research INC

Ryan J Whelan

Simmaron research INC

\section{Research Article}

Keywords: Myalgic Encephalomyelitis, chronic fatigue syndrome, ATG13, autophagy

Posted Date: September 29th, 2021

DOI: https://doi.org/10.21203/rs.3.rs-925403/v1

License: (c) (i) This work is licensed under a Creative Commons Attribution 4.0 International License.

Read Full License 


\section{Abstract}

Myalgic Encephalomyelitis and chronic fatigue syndrome is a multisystem illness characterized with extreme muscle fatigue associated with pain, neurocognitive impairment, and chronic inflammation. Despite intense investigation, the molecular mechanism of this disease is still unknown. Here we report two independent case-control studies to demonstrate that autophagy proteins are strongly upregulated in the serum of ME/CFS patients indicative of severe impairment in metabolic events of autophagy. Serum samples collected from two healthy and two age-matched patients were assayed for protein aggregation, screened for autophagy-related factors via an antibody array, quantified with densitometric analyses, and finally reconfirmed with ELISA analyses. Based on that double-blinded and gender-balanced study, the levels of ATG13, p62, and alpha-synuclein (a-syn) were found to be consistently elevated in the serum samples of these two ME/CFS patients. Moreover, our microglia-based oxidative stress response study and nitrite analyses indicated that serum samples of ME/CFS patients evoked the production of reactive oxygen species (ROS) and nitrite in human HMC3 microglial cells, whereas neutralization of ATG13 was shown to strongly diminish the production of ROS and nitrite demonstrating the de novo effect bloodborne autophagy factors on inducing the stress response in microglial cells. Collectively, our results indicate that the impairment of autophagy followed by upregulations of autophagy markers especially ATG13 in serum could be a pathological hallmark in ME/CFS.

\section{Introduction}

Autophagy is a biochemical process in which metabolically inactive proteins and defective mitochondria undergo hydrolysis in lysosomes $[1,2]$. During that process, dysfunctional cellular components are enclosed in vesicular structures known as "autophagosomes" and then fused with lysosome for subsequent hydrolytic degradation. Formation of autophagosome is a complex process guided with synchronized actions of multiple proteins. Proteins encoded by Autophagy related gene (ATG) family[3, 4], LC3/GABARAP family[5], p62[6], beclin-1[7], and VPS-34[8] primarily regulate the initiation, maturation, and lysosomal fusion of autophagosomes. On the other hand, cathepsin D[9], cathepsin B[10], LAMP1[11], and 50 different acid hydrolases[12] are lysosome-resident factors that directly participate in the degradation of these inactive proteins. Accordingly, impaired mechanisms of autophagy [13] coupled with lysosomal dysfunction [14] are responsible for the cellular deposition of aberrant protein aggregates and hence considered as a major contributing factor in the pathogenesis of many metabolic disorders such as Parkinson's disease (PD)[15-17], Alzheimer's disease (AD)[18, 19], stroke[20, 21], and cancers[22, 23]. However, autophagy impairment was never studied in ME/CFS. Historically, ME/CFS is a chronic multisystem disease[24], which is characterized with extreme muscle fatigue and muscular pain [25]. Chronic inflammation and cognitive deficit with poor attention span were also common pathological hallmarks of this disease. Until now, there is little known about the molecular mechanism of this disease.

Several reports indicate that the elevated levels of autophagy-related proteins in plasma can be directly correlated with the pathogenesis of many metabolic disorders. Upscaled detection of lysosomal 
Plasma ATG5 level is elevated in patients with Alzheimer's disease [28]. Beclin-1 and LC3, are observed in the serum in patients with acute ischemic stroke [29]. levels of autophagic markers might be associated with coronary total occlusion and childhood cerebral palsy [30,31]. Upregulation of a-syn was demonstrated in plasma of PD patients [32]. However, it is not known if these autophagy markers are also upregulated in ME/CFS.

To explore the molecular regulations of autophagy proteins, double-blinded antibody array analyses of 20 autophagy-related proteins were performed in the serum samples of two case-control subjects that demonstrated strong elevations of ATG13, p62 and a-syn. The result was further validated with ELISA analyses reconfirming that the expressions of ATG13, a-syn, and p62 were indeed strongly upregulated in the serum samples of both ME/CFS patients. Moreover, our in vitro cell culture study clearly demonstrated that the serum-derived ATG13 induced oxidative stress response and nitric oxide production in HMC3 human microglial cells. In summary, our current case study highlights that the molecular impairment of autophagy followed by elevation of autophagy markers in serum samples could be a pathological hallmark in ME/CFS.

\section{Results}

Clinical history of two subjects with ME/CFS displays significant muscle and cognitive impairments. In our current study, we included a 71 years old white male ME/CFS patient. Sometimes in 1988, when the subject was a 40 years old, he was initially diagnosed with acute flu-like symptom. The disease eventually progressed with severe symptomology of sore throat, acute joint pain, swollen cervical lymph nodes, mental fog, memory impairment, extreme dizziness, and severe fatigue leaving the patient bedridden for $90 \%$ of the time. Although, the underlying cause behind these symptoms was not determined, but subsequent antigen testing detected positive titers for EBV, HSV1, and CMV infection. In 1991, the patient was admitted to Dr. Peterson's clinic in a cluster of patients with similar clinical symptoms. A single-photon emission computerized tomography (SPECT) scan imaging analyses revealed that there was chronic Myalgic encephalomyelitis with bilateral hypoperfusion.

Another patient in our current study is currently a 67 years old female who had similar initial flu-like symptoms in 1988, which rapidly progressed to severe sinus infection with methicillin-resistant staphylococcus aureus (MRSA) infection. Eventually the patient received 6 turbinate surgeries. Although, the subject did not have any sinus problems, but has a history of depression, severe difficulty in sleeping (staying asleep specifically) and experiences fatigue, pain (general), IBS symptomology, severe memory impairment, and major brain fog. Recently the patient experienced extremely high blood pressure, with no noted cardiac dysfunction.

Both patients are classic cases of ME/CFS with extreme muscle fatigue and severe cognitive impairment. They routinely visit Dr. Peterson's clinic for their treatment regimen. Blood collection was performed with their consent and based on the guideline of approved IRB protocol. 
Autophagy-driven degradation of metabolically inactive protein is an important quality control process of cellular metabolism that directly regulates the function of muscle tissue [33] and also coordinates cognitive function[34]. Interestingly, both of these biological processes are significantly damaged in chronic fatigue syndrome, which intrigued us to study the impairment of autophagy in ME/CFS. Since autophagy impairment can be evaluated with the upscaled expressions of autophagy proteins in serum, next, we wanted to study the expressions of autophagy proteins in the serum of ME/CFS patients.

Estimation of protein aggregation propensities in serum samples of ME/CFS patients. Severe impairment in autophagy might result the increased tendency of protein aggregation in serum[35-37]. Therefore, first, we performed a thioflavin T (ThT)-based protein aggregation study in patient serum. The analysis is a fluorimetric tracking analysis that generates a sigmoidal evolution of protein from its liner structure to aggregated morphology. This type of kinetic study was previously done[38] in a cell-free system to analyze the kinetics of amyloid- $\beta$ protein aggregation[39]. In our present study, we adopted similar fluorimetric tracking study to explore if the serum proteins of ME/CFS patients have higher propensities to form aggregates. The accelerated rate of aggregation does not necessarily reflect the impairment of physiological mechanism of protein degradation; however, it might indicate that there is a higher tendency to form aberrant protein aggregates in serum samples of ME/CFS patients. Accordingly, serum samples of both 74 years old healthy control (Fig. 1A) and a 71 years old male ME/CFS (Fig. 1B) patient displayed increasing but non-liner pattern of aggregation as indicated with nonlinear fitted curves of Florescence intensities ( $486 \mathrm{~nm} / 450 \mathrm{~nm}$ ) with the function of increasing time from 0 to 90 minutes of ThT addition. The plotting equation is $\mathrm{y}=a_{1} x^{2}+a_{2} x+a_{3}$ with goodness of fit was determined as $\mathrm{R}^{2}$ $=0.9780$ ( 1 for liner) for healthy control and 0.9570 for patient. Interestingly, we observed that serum proteins of patient displayed significantly faster rate of protein aggregation compared to healthy control as indicated with steeper slope of $70.70 \pm 1.956$ in patient compared to relatively flat slope of $17.72 \pm$ 0.3806 in control (Fig. 1E). Moreover, the significance analysis revealed that there is a strong difference of protein aggregation rate in ME/CFS patient $\left[\mathrm{F}_{29,29}=15.99\left({ }^{\star \star \star} \mathrm{p}<0.0001\right)\right]$ compared to its gender-matched healthy control (Supplementary Table 1). Next, we performed a similar comparison study between a 68 years old healthy (Fig. 1C) female and a 67 years old female ME/CFS patient (Fig. 1D) that resulted a similar outcome of protein aggregation upon ThT addition. In that case-control study, we also observed a significantly faster aggregation of serum proteins in female patient compared to healthy control (Supplementary Table 1) $\left[\mathrm{F}_{29,29}=15.99\left({ }^{\star \star \star} \mathrm{p}<0.0001\right)\right]$. The non-liner fitted curve generated a steeper slope of $59.68 \pm 3.005$ in patient versus $19.36 \pm 1.599$ in healthy control (Fig. 1F). Taken together, our ThT assay revealed that serum samples of two ME/CFS patients have higher and faster propensity of protein aggregation compared to their age-matched and gender-balanced control.

Upregulations of autophagy markers in the serum of ME/CFS patients. Upregulations of autophagy markers in serum have been documented in many neurodegenerative and metabolic disorders. To evaluate these markers in ME/CFS, we performed a human autophagy antibody array analysis in the serum of two case-control subjects. Total protein concentration was assessed by Bradford procedure Loading [MathJax]/jax/output/CommonHTML/fonts/TeX/fontdata.js 
autophagy-related proteins (Supplementary Fig. 1C). After that, the signal was detected with IRDye800conjugated streptavidin and the image was captured in Li-Cor Odyssey Sa imager as discussed in method section. Surprisingly, we observed that expressions of ATG5, ATG7, ATG13, p62, Rheb, and a-syn were strongly upregulated in serum sample of 71-year-old ME/CFS patient (Fig. 2B; Supplementary Fig. 1B) compared to age-matched healthy subject (Fig. 2A; Supplementary Fig. 1A). The result was further confirmed with a densitometric analyses (Fig. 2C, 2D, 2E, 2F, 2G, and $2 \mathrm{H}$ are ATG 5, 7, 13, p62, Rheb, and a-syn respectively) with the significance of means calculated based on three independent experiments at $\star \star \star p<<0.0001$. To further confirm the result, we performed ELISA analyses of ATG5, ATG13, p62 and a-syn in serum sample of male ME/CFS patient with commercially available kits as described in method section. The detection sensitivity of these ELISA kits varies from lot to lot and also based on serum concentrations of proteins. Therefore, to demonstrate the accurate detection of these proteins, we adopted a dilution series of serum samples for ELISA-based detection of ATG5, ATG13, p62, and a-syn. Accordingly, a dose responsive non-liner fitting curve analysis followed by measuring $X$ intercept demonstrate that 1:4 dilution of serum provides most efficient detection of these serum-derived factors (Supplementary Fig. 2A-C). Subsequent ELISA analyses revealed that ATG5 (Fig. 2I), ATG13 (Fig. 2J), p62 (Fig. 2K), and a-syn (Fig. 2L) were strongly upregulated in serum samples of 71-year-old ME/CFS patients with most significant elevation in ATG13 level as evaluated with an unpaired t-test ( $* \star p<<0.0005=0.0003$ $v s$. healthy after 5 independent experiments). Although, ELISA is most reliable technology to quantify serum proteins, sometimes low signal-to-noise ratio of HRP detection method limits the accurate quantification[40]. In our manuscript, we introduced a novel near infrared-based ELISA method, which produces extremely sensitive detection of low abundance protein in serum mainly due to the high signalto-noise ratio of near-infrared probe[41]. Upon binding to biotinylated secondary antibody, IRDye-800 conjugated streptavidin produces extremely sharp signal at the end point that was detected in Li-Cor Odyssey Sa plate reader. Evidently, strong green signals representing upscaled abundance of ATG5 (Fig. 2M), ATG13 (Fig. 2N), p62 (Fig. 20), and a-syn (Fig. 2P) were observed in serum sample of 71-yearold ME/CFS male compared to low green signals indicative of low levels of these proteins in agematched control. The specificity of the signal was validated with no signal in $2^{\circ}$ antibody control whereas equal loading was verified with total albumin in respective serum samples. The result was further quantified with a densitometric analysis relative to total albumin concentrations (Supplementary Fig. 3A). Collectively, these results suggest that serum sample of 71-year-old male ME/CFS patient displayed upscaled expressions of ATG5, ATG13, p62, and a-syn, with maximum difference in ATG13.

Next, we performed similar antibody array analysis in the serum sample of 67-years-old female patient, which indicated significant elevations of LC3a, LC3b, p62, a-syn, and ATG-13 proteins (Fig. 3B: Supplementary Fig. 1D) compared to age-matched healthy control (Fig. 3A; Supplementary Fig. 1C). The result was further quantified with densitometric analyses (Fig. 3C-3G). To nullify the possibility of unequal loading of protein in array, we estimated the total protein concentration with Bradford method[42] and $1.5 \mathrm{mg}$ total protein was loaded on array membrane for each sample. Since antibody array is a semi-quantitative method to estimate serum protein, next we performed a quantitative ELISA

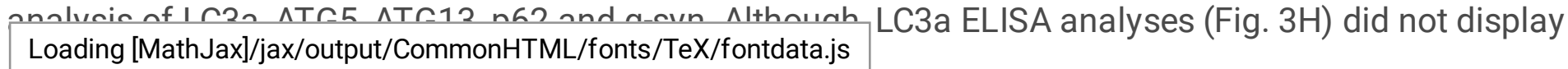


any significance, we observed strong elevations of ATG13 (Fig. 3I), p62 (Fig. 3J), and a-syn (Fig. 3K) in 67-years-old female ME/CFS patient compared to healthy control with maximum difference in ATG13 level $(\star \star \star p<0.001)$. Results were confirmed after five independent experiments.

To further confirm, we performed near-infrared ELISA assay for LC3a (Fig. 3L), ATG13 (Fig. 3M), p62 (Fig. 3N), and a-syn (Fig. 30) with albumin as loading control. Interestingly, similar to our quantitative ELISA method, no difference in LC3a expression was observed (Fig. 3L; Supplementary Fig. 3B). However, expressions of ATG13, p62, and a-syn were consistently higher in patient compared to healthy control (Fig. 3M-30: Supplementary Fig. 3B). In both case-control studies, we observed that serum levels of p62, a-syn and ATG13 were consistently elevated suggesting that these patients might have significant impairment in the formation of autophagosomes.

Evaluation of lysosomal function in ME/CFS patients. Upon enclosure in autophagosomes, cellular components are directed and fused to lysosomes for hydrolytic degradation[43]. Therefore, next, we wanted to evaluate if there is any lysosomal impairment in these patients. Lysosome is the home of cathepsin, a class of acid proteases that plays an essential role in the degradation of autophagic material and maintaining the cellular homeostasis of metabolism[44]. Therefore, lysosomal impairment can be evaluated by measuring the level of different cathepsins and other proteases. We adopted a human protease proteome profiler array, which can quantitatively detect 40 different blood-borne proteases (layout was shown in supplementary Fig. 4) including Cathepsins, Kallikreins, and matrix metalloproteinases. Interestingly, we did not observe any difference in the expression of lysosomal cathepsins between healthy control (Fig. 4A) and CFS male patient (Fig. 4B) as well as between female control (Fig. 4C) and female ME/CFS patient (Fig. 4D). Although, strong signals were observed for lysosomal proteases such as Cathepsin A (Fig. 4E), D (Fig. 4F), and X (Fig. 4G) in both case-control group, no significant difference was observed. We observed upregulation of cathepsins in male patient, however that difference did not pass t-test for the statistical significance. In contrast, we observed significant upregulation of extra-lysosomal proteases such as MMP-9 (Fig. 4H) and proteinase-3 (Fig. 4K) in male $\mathrm{ME} / \mathrm{CFS}$, but not female ME/CFS patient. Collectively, these results suggest that although there was significant impairment in the formation of autophagosomes, there was no abnormality in the expression of lysosomal proteases and a majority of other extra-lysosomal proteases.

Exploring the effect of autophagy marker ATG13 in the microglial stress response. Since we observed strong upregulations of ATG13 in serum samples of both patients, next we wanted to see if ATG13 plays any role in the pathogenesis of ME/CFS. Increase ROS production has been implicated in the pathogenesis of ME/CFS[45] and several other neuroinflammatory diseases such as MS[46], PD[47], and $A D[48]$. In order to explore the effect of ATG13 on microglial ROS production, we created an in vitro cell culture model (Fig. 5A), in which HMC3 human microglial cells were treated with serum-constituted DMEM media (1:1 v/v) followed by measuring ROS load in different time periods starting from 30 mins to $2 \mathrm{hrs}$ with DCFDA staining procedure[46]. As a control, healthy serum-constituted media was added on HMC3 cells and evaluated for ROS production. Interestingly, our immunofluorescence analyses (Fig. 5B) 
labelled ROS signal appeared as early as 30 minutes and reached maximum at $120 \mathrm{~min}$. This semiquantitative analyses was further confirmed with a real-time kinetic study (Fig. 5C), in which ROS production was measured at a ratio of $485 / 535 \mathrm{~nm}$ as a function of increasing time. Interestingly, we observed that serum sample of male patient increased microglial ROS production with increasing time, whereas healthy serum did not evoke any ROS production. Next, we performed similar fluorescence imaging (Fig. 5D) and kinetic (Fig. 5E) analyses with serum samples of female ME/CFS patient and agematched healthy control. Accordingly, we observed that patient serum elevated ROS production with increasing time. Taken together, these results established a new cell culture model to evaluate the ROSinducing capacity in serum samples of ME/CFS patients. With the aid of this model, we were able to quantify ROS-production in HMC3 human microglial cells upon stimulation with ME/CFS serum. Next, we wanted to study if ATG13 in ME/CFS serum enhances ROS production in HMC3 microglial cells. To study that, we adopted a neutralization technique (Fig. 5A; lower panel), in which patient sera were added on a 96 well plate, which is coated with ATG13 neutralization antibody. After 30 minutes, ATG13-depleted sera were harvested from the top and then proceeded with a similar sets of experiments to evaluate microglial ROS production. Interestingly, ATG13 depletion from the sera of both male (Fig. 5F) and female patients (Fig. 5G), significantly attenuated the production of ROS in HMC3 cells suggesting a direct role of serumderived ATG13 in stimulating oxidative stress in microglial cells. Microglial production of nitric oxide (NO) also plays an important role in the pathogenesis of neuroinflammatory diseases[46, 49]. Next, we wanted to study if ATG13 could directly stimulate nitrite production in microglia. Surprisingly, Stimulation of HMC3 microglial cells with increasing doses $(1,2,5$, and $10 \mathrm{ng} / \mathrm{mL})$ of ATG13 protein alone induced nitrite production (Fig. 6A). The nitrite production was compared with positive control LPS. Although, ATG13-stimulated nitrite production was almost 2-times lower than that of LPS stimulation, combination of $1 \mathrm{ng} / \mathrm{mL}$ ATG13 with $0.5 \mu \mathrm{g} / \mathrm{mL}$ LPS stimulated the production of nitrite on a par with $1 \mu \mathrm{g} / \mathrm{mL}$ LPS. Accordingly, 1:4 (25 $\mu \mathrm{L}$ serum $+75 \mu \mathrm{L}$ serum-free DMEM/F12 media) and 1:2 (50 $\mu \mathrm{L}$ serum $+50 \mu \mathrm{L}$ serum-free DMEM/F12 media) dilution ( $\mathrm{v} / \mathrm{v}$ ) of serum from male ME/VFS patient dose-dependently stimulated nitrite production in HMC3 microglial cells. On the other hand, we observed that depletion of ATG13 significantly ablated the ability of the patient's serum to stimulate nitrite production in HMC3 cells. Taken together, these results suggest that elevated ATG13 in the serum of ME/CFS patients directly stimulates oxidative stress and nitrite production in microglial cells.

Regulation of ATG13 in the serum samples of ME/CFS patients. Next, we wanted to measure ATG13 level and levels of other autophagy-related proteins such as ATG5 and p62 in the sera of 12 ME/CFS patients and 12 healthy controls. The cohort of 24 samples from Dr. Peterson's clinic was randomly selected and displayed with their age, ethnicity, and gender in a table (Table 1). Briefly, serum samples were diluted (1:4 dilution $=25 \mu \mathrm{L}$ serum $+75 \mu \mathrm{L}$ sample diluent) and then assayed with competitive ELISA technique for ATG13 (Fig. 7A), ATG5 (Fig. 7B), LC3a (Fig. 7C), and p62 (Fig. 7D). Quantification was performed based on the standard curve equation as shown in supplementary Fig. 5. Interestingly, we observed that ATG13 levels are higher in 10 patients (out of 12) compared to 10 healthy controls (total 12). No difference was observed while comparing the levels of ATG5, LC3a, and p62. Taken together, our results suggest that 
dysregulation of autophagy resulting the release of ATG13 in the serum of ME/CFS patients stimulates the oxidative stress response and nitric oxide production in microglial cells. 
Table 1

Gender, ethnicity, age, disease status, and serum ATG13 ( \pm SD) levels in a cohort of 24 subjects (12 healthy and $12 \mathrm{ME} / \mathrm{CFS}$ ). High or low was determined with reference to mean (=4.8030). Expression above mean is considered to be high and below mean is considered to be low. Red $=$ disease and Blue $=$ control. OI = orthostatic intolerance; SFN = small fiber polyneuropathy; POTs = Postural Orthostatic

Tachycardia.

\begin{tabular}{|c|c|c|c|c|c|c|c|}
\hline $\mathrm{S} / \mathrm{N}$ & Status & Age & Gender & Ethnicity & $\begin{array}{l}\text { Disease } \\
(\mathrm{Y} / \mathrm{N})\end{array}$ & $\begin{array}{l}\text { ATG13 } \\
\mathrm{ng} / \mathrm{mL}\end{array}$ & $\begin{array}{l}\text { ATG13 } \\
\text { (High/low) }\end{array}$ \\
\hline 1 & Control & 58 & $\mathrm{~F}$ & W & $\mathrm{N}$ & 5.2438 & high \\
\hline 2 & Control & 60 & $\mathrm{~F}$ & W & $\mathrm{N}$ & 3.8755 & low \\
\hline 3 & Control & 44 & $\mathrm{~F}$ & W & $\mathrm{N}$ & 1.3909 & low \\
\hline 4 & $\begin{array}{l}\text { CFS }+ \text {, Ol+, POTS+, } \\
\text { SFN+ }\end{array}$ & 72 & $\mathrm{~F}$ & W & $Y$ & 11.299 & high \\
\hline 5 & SFN + only, no CFS & 83 & $M$ & W & Y & 1.6975 & low \\
\hline 6 & Control & 66 & $\mathrm{~F}$ & W & $\mathrm{N}$ & -4.298 & low \\
\hline 7 & CFS+, Ol+, POTS+ & 40 & $\mathrm{~F}$ & W & Y & 45.380 & Very high \\
\hline 8 & Control & 25 & M & W & $\mathrm{N}$ & 3.933 & low \\
\hline 9 & $\mathrm{CFS}+, \mathrm{OI}+, \mathrm{SFN}+$ & 66 & $\mathrm{~F}$ & W & $Y$ & 7.559 & high \\
\hline 10 & $\mathrm{CFS}+, \mathrm{Ol}+, \mathrm{SFN}+$ & 65 & $M$ & W & Y & 4.999 & high \\
\hline 11 & Control & 59 & $\mathrm{~F}$ & W & $\mathrm{N}$ & 2.061 & low \\
\hline 12 & Control & 59 & $\mathrm{~F}$ & W & $\mathrm{N}$ & 22.547 & high \\
\hline 13 & Control & 67 & $M$ & W & $\mathrm{N}$ & -7.765 & low \\
\hline 14 & Control & 55 & M & W & $\mathrm{N}$ & -2.682 & Low \\
\hline 15 & CFS + only & 73 & M & W & $Y$ & 15.436 & high \\
\hline 16 & Control & 68 & $\mathrm{~F}$ & W & $\mathrm{N}$ & -1.029 & low \\
\hline 17 & CFS + only & 33 & M & W & $Y$ & 13.490 & high \\
\hline 18 & Control & 32 & $M$ & W & $\mathrm{N}$ & -6.861 & low \\
\hline 19 & $\mathrm{CFS}+, \mathrm{Ol}+, \mathrm{SFN}+$ & 28 & $\mathrm{~F}$ & W & $Y$ & 7.8578 & high \\
\hline 20 & $\mathrm{CFS}+, \mathrm{OI}+, \mathrm{SFN}+$ & 65 & $\mathrm{~F}$ & W & $Y$ & 16.087 & high \\
\hline 21 & Control & 65 & $M$ & W & $\mathrm{N}$ & -0.6706 & low \\
\hline 22 & CFS+, Ol+ & 56 & $\mathrm{~F}$ & W & $Y$ & 6.51124 & high \\
\hline 23 & CFS+, Ol+ & 61 & $\mathrm{~F}$ & W & $Y$ & -9.1545 & low \\
\hline Loa & & & & & Y & 7.377 & high \\
\hline
\end{tabular}




\section{Discussion}

Several lines in our current report highlighted that there could be a strong impairment of autophagy function in ME/CFS patients. First, a ThT-based protein aggregation study revealed that serum samples of ME/CFS patients had significantly higher propensity to form aberrant protein aggregation indicative of potential autophagy impairment, which is an essential pathway for these protein to be targeted and degraded in lysosomes. Second, our dot blot antibody array analyses indicated that serum levels of, ATG5, ATG7, ATG13, p62, and a-syn were strongly elevated in 71 years old male ME/CFS patient. Third, similar antibody array analysis in a 67 years old female patient detected significantly high levels of ATG13, LC3a, LC3b, p62, and asyn. Fourth, our immunoblot analyses further confirmed that there were strong upregulations of p62, a-syn, and LC3 levels in serum of these patients. The result was further corroborated with densitometric analyses. All these results combinedly suggest that there is a substantial impairment of autophagy in these two cases.

We observed that levels of ATG5, ATG7, and ATG13 were strongly elevated in a 71-years old male ME/CFS patient, whereas only ATG13 was significantly upregulated in 67 years old female ME/CFS patient A recent report suggests that upscaled detection of ATG proteins, specifically ATG5 and ATG12, in serum potentially indicates progressive neuronal damage in brain of $A D$ patients. Aberrant aggregation of Amyloid- $\beta$ in AD brain stimulates the impairment of autophagy resulting the release of ATG5 and ATG12 in CSF and blood serum. Therefore, a strong impairment of autophagy and subsequent release of autophagy marker proteins such as ATG5 in blood could be a reliable indicator of cognitive impairment in ME/CFS patient. In fact, 71 years old ME/CFS patient has significant cognitive impairment and memory loss. Additionally, we observed a strong upregulation of a-syn in serum of that male patient indicating a potential relationship of alpha-synucleinopathy[50-52] and Lewybody dementia[52] with ME/CFS.

Although the detection of ATG13 in blood serum was unexpected, we observed a strong upregulation of ATG13 in 67 years old female ME/CFS patient. ATG13 is an important factor for cardiac development as atg13 deficient mouse displays growth retardation and severe deficit in cardiac development[53]. A recent study[54] indicates that during myocardial infarction plasma level of atg13 rises and selective inhibition of circulating ATG13 benefits the protection against myocardial infarction and other cardiovascular impairments. Interestingly, that female patient in our present study suffers from cardiovascular abnormalities with exceptionally high blood pressure. Therefore, high level of circulating ATG3 might account for the high blood pressure in that patient. Interestingly, ATG13 also regulates the expression of antiviral interferon $\beta$ to restrict viral infection and plays an essential role in innate immune response to provide antiviral immunity[55]. Therefore, functional deficiency of atg13 gene increases the susceptibility to viral infection and viral reactivation. Both are very common in ME/CFS patients. Moreover, our results further demonstrated that ATG13 alone stimulated the oxidative and nitosylative stress response in microglial cells, whereas selective ablation of ATG13 in serum of ME/CFS patient ameliorated oxidative stress response in microglial cells. 
Further characterization of serum ATG13 is mandated. ATG13 participates in the early stage of autophagy vesicle formation process via forming a complex of ULK1 (unc-51 like autophagy activating kinase 1), FIP200 [56], and ATG101 [57]. Activation of mammalian target of rapamycin (mTOR) directly causes hyperphosphorylation of ATG13 in multiple serine residues [58], inhibits the formation of ULK1 complex, and subsequently aborts the autophagy process resulting the accumulation of aberrant proteins and depolarized mitochondria in the biologically active cell. Therefore, characterization of hyperphosphorylated (or nitrosylated?) form of ATG13 is mandated in the serum of ME/CFS patients.

ME/CFS patients are highly heterogeneous in terms of pathophysiological outcomes and serum marker proteins. Although, serum levels of p62 and ATG5 were found to be elevated in both of our case studies, we did not see any detectable amount of ATG5 and LC3 in a cohort of serum samples of $10 \mathrm{ME} / \mathrm{CFS}$ and 10 healthy subjects. Taken together, our current case study provides a molecular evidence of autophagy impairment in ME/CFS.

\section{Materials And Methods}

Reagents: Human autophagy array ki (Cat \# AAH-ATG-1-4) was purchased from RayBiotech (Georgia, USA). Human p62/SQSTM1 ELISA kit (Cat\# MBS3801969), Autophagy protein 5 (ATG5) ELISA kit (Cat\# MBS7209535), ATG13 ELISA kit (Cat\# MBS7239399), LC3A ELISA kit (Cat\# MBS7253712), and a-syn ELISA kit (Cat \# MBS161176) were purchased from My BioSource (San Diego, Southern California, USA). IRDye800-conjugated anti-rabbit and anti-mouse antibodies were purchased from LI-COR biosciences (Lincoln, NE). IRDye800-conjugated streptavidin (Cat\# 926-32230) was also purchased from LI-COR for the endpoint detection of human autophagy array in Odyssey SA infrared imager. Thioflavin T (Cat \# T3516) and ammonium sulphate (Cat \# A4418) were purchased from Sigma. HMC3 human transformed microglial cell lines ( ATCC $\AA$ CRL-3304 ${ }^{\mathrm{TM}}$ ) were purchased from ATCC and maintained with complete DMEM media supplemented with 10\% FBS (Lot \# 2346974RP; Gibco), 2 mM L-glutamine (Ref\# 25030081: Gibco), and antibiotic-antimycotic. All media supplements were purchased from Thermofisher scientific. $\mathrm{CO}_{2}$ gas was supplied by Sheeley Service INC (Milwaukee, WI).

\section{Acquisition of samples and handling patient record}

Blood samples and questionnaire data were previously collected under the supervision of Dr. Daniel Peterson (Western IRB) \#20201812. Blood samples were collected, centrifuged and serum samples were aliquoted then frozen at $-80^{\circ} \mathrm{C}$ immediately. Each sample was given a unique identification number and recorded both in notebook and Microsoft Excel with date and signature per the IRB approved protocol. Samples were then delivered to our research facility in Wisconsin from Sierra Internal Medicine on dry ice overnight via FedEx. Upon receipt, samples are collected, processed, and assayed immediately.

Questionnaire and de-identified clinical data are stored in secure, limited access Redcap sever database managed by the Research Staff and Clinical Fellow at Sierra Internal Medicine. Patient record was disclosed and documented with proper HIPPA privacy policy guideline set by Sierra internal medicine. 
Antibody array: RayBio ${ }^{\circledR}$ C-series Human Autophagy Array was performed as described in manufacturer's protocol. Array membrane was engraved with 20 autophagy related proteins in duplicate in $8 \times 8$ format. Briefly, each membrane was soaked with blocking buffer for $1 \mathrm{hr}$, incubated with 1:5 diluted serum samples (1.4 mg protein as measured with Bradford protein detection method) for $5 \mathrm{hrs}$ at $37^{\circ} \mathrm{C}$, washed 5 times with $1 \mathrm{X}$ wash buffer, incubated with biotin-conjugated secondary antibody for $2 \mathrm{hrs}$ at $37^{\circ} \mathrm{C}$ followed by wash (5X) and detection with IRDye800-conjugated streptavidin at Licor Odyssey Sa infrared scanner. All necessary reagents and antibodies were supplied with the kit except IRDye800conjugated streptavidin as the application of streptavidin conjugate was devised for the detection of membrane in Sa scanner. Scanning process was done at resolution of $200 \mu \mathrm{m}$ with focus offset at 3.0 $\mathrm{mm}$. Density of individual protein was measured in ImageJ software, subtracted from blank, normalized with positive control, and then plotted at GraphPad Prism 8 software.

Colorimetric Competitive ELISA: Colorimetric ELISA was performed as per manufacturers protocol supplied with kits from MyBioSource INC. (San Diego, CA). Briefly, serum samples were diluted with assay diluent at a dilution of 1:4 (v/v) and incubated on a 96 well strip plate with well pre-coated with capture antibodies followed by 30 minutes incubation at room temperature (r.t) in a shaking condition. After that, biotinylated assay conjugate was added and incubated for $24 \mathrm{hrs}$ at $4^{\circ} \mathrm{C}$. After that, each well was aspirated, washed 3 times, and then added HRP-conjugated detection antibody followed by incubation for $2 \mathrm{hrs}$ at r.t. under shaking condition. After that, each well was aspirated followed by developing color with TMB substrate. Optical density was measured at $450 \mathrm{~nm}$ excitation filter at Victor X3 multi-channel plate reader. According to competitive ELISA, more color indicates less abundance of the target in serum resulting a non-liner regression standard curve with negative slope. The optical density $(\mathrm{Y})$ was converted to absolute amount $(X)$ with following equation $Y=$ Bottom+(Top-Bottom $) /[1+(X / I C 50)]$ using GraphPad Prism 8.

\section{Near infra-red ELISA}

After overnight incubation with sample in a pre-coated 96 well plate probed with biotinylated secondary antibodies for 2 hrs. biotin conjugation of polyclonal anti-ATG13 (Host; Rabbit; Cat\# 18258-1-AP; Proteintech), ATG5 (Host; Rabbit; Cat\# 10181-2-AP; Proteintech), and LC3a antibodies (Host; Rabbit; Cat\# 18722-1-AP; Proteintech) were performed with SiteClick ${ }^{\text {TM }}$ Biotin Antibody Labeling Kit purchased from Thermofisher (Cat \# S20033). After that, IRDye800-conjugated STREPTAVIDIN was probed for $2 \mathrm{hrs,}$ imaged in LI-COR Odyssey SA scanner, and finally analyzed with integrated density measurement tool at Odyssey Sa imager.

Fluorometric Thioflavin T assay: Serum samples were centrifuged at $800 \mathrm{rpm}$ to get rid of the macromolecular impurities followed by measuring the protein concentration using BCA method. After that, $5 \mu \mathrm{L}$ serum ( $200 \mu \mathrm{g}$ of proteins) was mixed with $4 \mathrm{M}$ ammonium sulfate (55mg in $1 \mathrm{~mL} \mathrm{ddH20}$ ) solution and then plated in a 96 well plate (reaction volume is $100 \mu \mathrm{L}$ ). After that, diluted (1:5 in 1X PBS) Thioflavin T (ThT) solution (stock: $8 \mathrm{mg}$ of ThT in $1 \mathrm{X} \mathrm{PBS}$; kept in dark at $4^{\circ} \mathrm{C}$ ) was dispensed via an auto- 
dispenser and plate reading was performed immediately in Victor X3 fluorescent plate-reader with $450 \mathrm{~nm}$ excitation and $486 \mathrm{~nm}$ emission wavelengths for 90 minutes at 3 minute interval.

\section{ATG13 neutralization study}

$100 \mu \mathrm{L}$ serum samples were diluted with $100 \mu \mathrm{L}$ sterile DMEM supplemented with protease inhibitors [2 $\mu \mathrm{g} / \mathrm{ml}$ aprotinin (Cat \# 78432; Thermofisher), $1 \mu \mathrm{g} / \mathrm{ml}$ leupeptin (Cat\# 78435; Thermofisher), and 25 $\mu \mathrm{g} / \mathrm{ml} \mathrm{PMSF}$ (Cat\# 36978; Thermofisher)] followed by addition on a 96-well plate precoated with ATG13 capture antibody. After 30 mins of incubation at $37^{\circ} \mathrm{C}$, the media was carefully harvested from the top and used for subsequent experiment. The neutralization of ATG13 was confirmed with ELISA analyses in serum before and after neutralization.

Microglia Cell culture, fluorimetric ROS assay, and microscopy: HMC3 human embryonic microglial cells were thawed from liquid nitrogen, immediately poured in $15 \mathrm{~mL}$ of fresh complete DMEM/F12 media kept in a $75 \mathrm{~mm}$ flat surface sterile tissue culture flask, and then placed inside a temperature-controlled $\mathrm{CO} 2$ incubator $\left(37^{\circ} \mathrm{C} / 5 \% \mathrm{CO}_{2}\right)$. After 2 days, media was replaced with $15 \mathrm{~mL}$ of fresh DMEM/F12 complete media. After 10 days when cells were confluently growing, passaging was performed. After 3 passaging cells were harvested and plated in a 96well-plate for ROS fluorimetric and kinetic study. Cells were allowed to grow at 75-80\% confluency, incubated with DCFDA probe (Cat\# ab113851; Abcam) for 45 mins at $37^{\circ} \mathrm{C}$ in dark, replaced media with $100 \mu \mathrm{L}(1: 2$ dilution $=50 \mu \mathrm{L}$ serum $+50 \mu \mathrm{L}$ media) serumsupplemented media, and then waited for different time period starting from 30 mins to $2 \mathrm{hrs}$. At the end of incubation period, media was aspirated and then imaged under FITC channel of Hund fluorescence microscope. For kinetic assay, media was not aspirated. Media embedded cells were kept at VictorX3 fluorimeter at different time point and reading was recorded at $485 \mathrm{~nm} / 53 \mathrm{~m} \mathrm{~nm}(\mathrm{Ex} / \mathrm{Em})$ fluorescence reading protocol.

\section{Nitrite assay}

Nitric oxide assay[49] was performed as described before according to Griess method (Cat \# GS921;Thermofisher).

Double blinding and statistical analysis. All assay were performed with double-blinded strategy, in which researcher \#1 (AR) was be blinded by researcher \# 2 (KK) with sample identification. Samples were tagged with different color tag by KK and handed over to AR. KK was not aware of disease status of the subject (blinding \# 2). The unique color code was decoded once the assay completed, and result was disclosed in the presence of both researchers, consultant, and physician. Finally, the data was plotted in GraphPad Prism 8 software and significance of mean was tested with an unpaired t-test at $95 \%$ significance interval and $p<0.05$.

\section{Declarations}


Acknowledgement: This work was funded by Simmaron Research INC, a non-profit 501C research organization, Incline village, NV 89451.

Data availability Statement: There is no electronic datasheet associated with this paper. Raw blots, standard curve of ELISA, and layout of the array were included in the supplemental file. Data associated with patients' clinical history has been preserved and restricted by Western IRB to DP. No data in electronic repository.

Ethical Statement: Acquisition of patients' serum, documentation of questionnaire, collection of written consent, and other procedures in this study were conducted in accordance with the Sierra internal medicine-approved western IRB \# 20201812 protocol.

Contributions of authors: GC, RW, MM, KK, and AR conducted experiments; DP has IRB and in charge of human samples; AR conceived the idea and wrote the manuscript.

Declaration: Authors declare no conflict of interest.

\section{References}

1. Mizushima N (2007) Autophagy: process and function. Genes Dev 21:2861-2873

2. Rabinowitz JD, White E (2010) Autophagy and metabolism. Science 330:1344-1348

3. Noda NN, Fujioka Y (2015) Atg1 family kinases in autophagy initiation. Cell Mol Life Sci 72:30833096

4. Mizushima N (2020) The ATG conjugation systems in autophagy. Curr Opin Cell Biol 63:1-10

5. Tanida I, Ueno T, Kominami E (2008) LC3 and Autophagy. Autophagosome and phagosome. Springer, pp 77-88

6. Moscat J, Diaz-Meco MT (2009) p62 at the crossroads of autophagy, apoptosis, and cancer. Cell 137:1001-1004

7. He C, Levine B (2010) The beclin 1 interactome. Curr Opin Cell Biol 22:140-149

8. Jaber N, Dou Z, Chen J-S, Catanzaro J, Jiang Y-P, Ballou LM, Selinger E, Ouyang X, Lin RZ, Zhang J (2012) Class III PI3K Vps34 plays an essential role in autophagy and in heart and liver function.

Proceedings of the National Academy of Sciences 109:2003-2008

9. Benes P, Vetvicka V, Fusek M (2008) Cathepsin D-many functions of one aspartic protease. Crit Rev Oncol Hematol 68:12-28

10. Mort JS, Buttle DJ (1997) Cathepsin b. Int J Biochem Cell Biol 29:715-720

11. Eskelinen E-L (2006) Roles of LAMP-1 and LAMP-2 in lysosome biogenesis and autophagy. Mol Aspects Med 27:495-502

12. Saftig P (2006) Physiology of the lysosome. Fabry disease: perspectives from 5 years of FOS 
13. Komatsu M, Waguri S, Chiba T, Murata S, Iwata J, Tanida I, Ueno T, Koike M, Uchiyama Y, Kominami E, Tanaka K (2006) Loss of autophagy in the central nervous system causes neurodegeneration in mice. Nature 441:880-884. doi:10.1038/nature04723

14. Zhang Z, Yue P, Lu T, Wang Y, Wei Y, Wei X (2021) Role of lysosomes in physiological activities, diseases, and therapy. J Hematol Oncol 14:79. doi:10.1186/s13045-021-01087-1

15. Lane JD, Korolchuk VI, Murray JT, Karabiyik C, Lee MJ, Rubinsztein DC (2017) Autophagy impairment in Parkinson's disease. Essays Biochem 61:711-720

16. Ahmed I, Liang Y, Schools S, Dawson VL, Dawson TM, Savitt JM (2012) Development and characterization of a new Parkinson's disease model resulting from impaired autophagy. J Neurosci 32:16503-16509

17. Cerri S, Blandini F (2019) Role of autophagy in Parkinson's disease. Curr Med Chem 26:3702-3718

18. Nassif M, Hetz C (2012) Autophagy impairment: a crossroad between neurodegeneration and tauopathies. BMC Biol 10:1-4

19. Kragh CL, Ubhi K, Wyss-Corey T, Masliah E (2012) Autophagy in dementias. Brain pathology 22:99109

20. Luo T, Park Y, Sun X, Liu C, Hu B (2013) Protein misfolding, aggregation, and autophagy after brain ischemia. Translational stroke research 4:581-588

21. Liu C, Gao Y, Barrett J, Hu B (2010) Autophagy and protein aggregation after brain ischemia. Journal of neurochemistry 115:68-78

22. White $\mathrm{E}$ (2012) Deconvoluting the context-dependent role for autophagy in cancer. Nature reviews cancer 12:401-410

23. Mathew R, Karantza-Wadsworth V, White E (2007) Role of autophagy in cancer. Nat Rev Cancer 7:961-967

24. (2015) Beyond Myalgic Encephalomyelitis/Chronic Fatigue Syndrome: Redefining an IIIness. Mil Med 180:721-3. doi: 10.7205/MILMED-D-15-00085

25. Gerwyn M, Maes M (2017) Mechanisms explaining muscle fatigue and muscle pain in patients with myalgic encephalomyelitis/chronic fatigue syndrome (ME/CFS): A review of recent findings. Curr Rheumatol Rep 19:1

26. Ranierri E, Gerace RL, Ravenscroft EM, Hopwood JJ, Meikle PJ (1999) Pilot neonatal screening program for lysosomal storage disorders, using lamp-1. Southeast Asian J Trop Med Public Health 30(Suppl 2):111-113

27. Meikle PJ, Brooks DA, Ravenscroft EM, Yan M, Williams RE, Jaunzems AE, Chataway TK, Karageorgos LE, Davey RC, Boulter CD, Carlsson SR, Hopwood JJ (1997) Diagnosis of lysosomal storage disorders: evaluation of lysosome-associated membrane protein LAMP-1 as a diagnostic marker. Clin Chem 43:1325-1335

28. Cho SJ, Lim HJ, Jo C, Park MH, Han C, Koh YH (2019) Plasma ATG5 is increased in Alzheimer's disease. Sci Rep 9:4741. doi:10.1038/s41598-019-41347-2

Loading [MathJax]/jax/output/CommonHTML/fonts/TeX/fontdata.js

Page 15/25 
29. Li H, Qiu S, Li X, Li M, Peng Y (2015) Autophagy biomarkers in CSF correlates with infarct size, clinical severity and neurological outcome in AIS patients. J Transl Med 13:359. doi:10.1186/s12967-015-0726-3

30. Demircan G, Kaplan O, Ozdas SB (2018) Role of autophagy in the progress of coronary total occlusion. Bratisl Lek Listy 119:103. doi:10.4149/BLL_2018_019

31. Xu J, Xia L, Shang Q, Du J, Zhu D, Wang Y, Bi D, Song J, Ma C, Gao C, Zhang X, Sun Y, Zhu L, Wang X, Zhu C, Xing Q (2017) A Variant of the Autophagy-Related 5 Gene Is Associated with Child Cerebral Palsy. Front Cell Neurosci 11:407. doi:10.3389/fncel.2017.00407

32. Bougea A, Stefanis L, Paraskevas GP, Emmanouilidou E, Vekrelis K, Kapaki E (2019) Plasma alphasynuclein levels in patients with Parkinson's disease: a systematic review and meta-analysis. Neurol Sci 40:929-938. doi:10.1007/s10072-019-03738-1

33. Sebastian D, Zorzano A (2016) When MFN2 (mitofusin 2) met autophagy: A new age for old muscles. Autophagy 12:2250-2251. doi:10.1080/15548627.2016.1215383

34. Glatigny M, Moriceau S, Rivagorda M, Ramos-Brossier M, Nascimbeni AC, Lante F, Shanley MR, Boudarene N, Rousseaud A, Friedman AK, Settembre C, Kuperwasser N, Friedlander G, Buisson A, Morel E, Codogno P, Oury F (2019) Autophagy Is Required for Memory Formation and Reverses AgeRelated Memory Decline. Curr Biol 29:435-448 e8. doi:10.1016/j.cub.2018.12.021

35. Sharma S (2018) Autophagy-Based Diagnosis of Pregnancy Hypertension and Pre-Eclampsia. Am J Pathol 188:2457-2460. doi:10.1016/j.ajpath.2018.09.001

36. Magalhães S, Trindade D, Martins T, Rosa IM, Delgadillo I, Goodfellow BJ, e Silva OAdC, Henriques $A G$, Nunes A (2020) Monitoring plasma protein aggregation during aging using conformationspecific antibodies and FTIR spectroscopy. Clin Chim Acta 502:25-33

37. Giacomelli C, Daniele S, Martini C (2017) Potential biomarkers and novel pharmacological targets in protein aggregation-related neurodegenerative diseases. Biochem Pharmacol 131:1-15

38. Batzli KM, Love BJ (2015) Agitation of amyloid proteins to speed aggregation measured by ThT fluorescence: a call for standardization. Mater Sci Eng C Mater Biol Appl 48:359-364. doi:10.1016/j.msec.2014.09.015

39. Meng F, Marek P, Potter KJ, Verchere CB, Raleigh DP (2008) Rifampicin does not prevent amyloid fibril formation by human islet amyloid polypeptide but does inhibit fibril thioflavin-T interactions: implications for mechanistic studies of $\beta$-cell death. Biochemistry 47:6016-6024

40. Motsenbocker M (1988) Sensitivity limitations encountered in enhanced horseradish peroxidase catalysed chemiluminescence. J Biolumin Chemilumin 2:9-16

41. Jensen PS, Bak J (2002) Near-infrared transmission spectroscopy of aqueous solutions: Influence of optical pathlength on signal-to-noise ratio. Appl Spectrosc 56:1600-1606

42. Bradford MM (1976) A rapid and sensitive method for the quantitation of microgram quantities of protein utilizing the principle of protein-dye binding. Anal Biochem 72:248-254

43. Lorincz P, Juhasz G (2020) Autophagosome-Lysosome Fusion. J Mol Biol 432:2462-2482. 
44. Repnik U, Stoka V, Turk V, Turk B (2012) Lysosomes and lysosomal cathepsins in cell death. Biochim Biophys Acta 1824:22-33. doi:10.1016/j.bbapap.2011.08.016

45. Medow MS, Aggarwal A, Baugham I, Messer Z, Stewart JM (2013) Modulation of the axon-reflex response to local heat by reactive oxygen species in subjects with chronic fatigue syndrome. J Appl Physiol (1985) 114:45-51. doi:10.1152/japplphysiol.00821.2012

46. Roy A, Jana A, Yatish K, Freidt MB, Fung YK, Martinson JA, Pahan K (2008) Reactive oxygen species up-regulate CD11b in microglia via nitric oxide: Implications for neurodegenerative diseases. Free Radic Biol Med 45:686-699

47. Roy A, Ghosh A, Jana A, Liu X, Brahmachari S, Gendelman HE, Pahan K (2012) Sodium phenylbutyrate controls neuroinflammatory and antioxidant activities and protects dopaminergic neurons in mouse models of Parkinson's disease. PLoS One 7:e38113. doi:10.1371/journal.pone.0038113

48. Modi KK, Roy A, Brahmachari S, Rangasamy SB, Pahan K (2015) Cinnamon and Its Metabolite Sodium Benzoate Attenuate the Activation of p21 rac and Protect Memory and Learning in an Animal Model of Alzheimer's Disease. PLoS One 10:e0130398. doi:10.1371/journal.pone.0130398

49. Roy A, Fung YK, Liu X, Pahan K (2006) Up-regulation of microglial CD11b expression by nitric oxide. J Biol Chem 281:14971-14980

50. Roy A, Rangasamy SB, Kundu M, Pahan K (2016) BPOZ-2 gene delivery ameliorates alphasynucleinopathy in A53T transgenic mouse model of parkinson's disease. Scientific reports 6:1-14

51. Roy A, Pahan K (2013) Ankyrin repeat and BTB/POZ domain containing protein-2 inhibits the aggregation of alpha-synuclein: implications for Parkinson's disease. FEBS Lett 587:3567-3574

52. Roy A (2016) Targeting BPOZ-2 in Lewy body disease. Neural regeneration research 11:910

53. Kaizuka T, Mizushima N (2015) Atg13 is essential for autophagy and cardiac development in mice. Mol Cell Biol 36:585-595

54. Zhao P, Zhu Y, Sun L, Zhu W, Lu Y, Zhang J, Mao Y, Chen Q, Zhang F (2021) Circulating Exosomal miR-1-3p from Rats with Myocardial Infarction Plays a Protective Effect on Contrast-Induced Nephropathy via Targeting ATG13 and activating the AKT Signaling Pathway. Int J Biol Sci 17:972985. doi:10.7150/ijbs.55887

55. Du JL, Ma P, Wang C, Zeng Y, Xue YJ, Yang XC, Wan XM, Chang FF, Zhao TY, Jia XY, Wang HZ, Liu J, Ma ZR, Cao X, Cai KZ (2019) ATG13 restricts viral replication by induction of type I interferon. J Cell Mol Med 23:6508-6511. doi:10.1111/jcmm.14483

56. Hara T, Takamura A, Kishi C, lemura S, Natsume T, Guan JL, Mizushima N (2008) FIP200, a ULKinteracting protein, is required for autophagosome formation in mammalian cells. J Cell Biol 181:497-510. doi:10.1083/jcb.200712064

57. Zachari M, Ganley IG (2017) The mammalian ULK1 complex and autophagy initiation. Essays Biochem 61:585-596. doi:10.1042/ebc20170021

58. Puente C, Hendrickson RC, Jiang X (2016) Nutrient-regulated Phosphorylation of ATG13 Inhibits

Loading [MathJax]/jax/output/CommonHTML/fonts/TeX/fontdata.js 5-6035. doi:10.1074/jbc.M115.689646

Page $17 / 25$ 

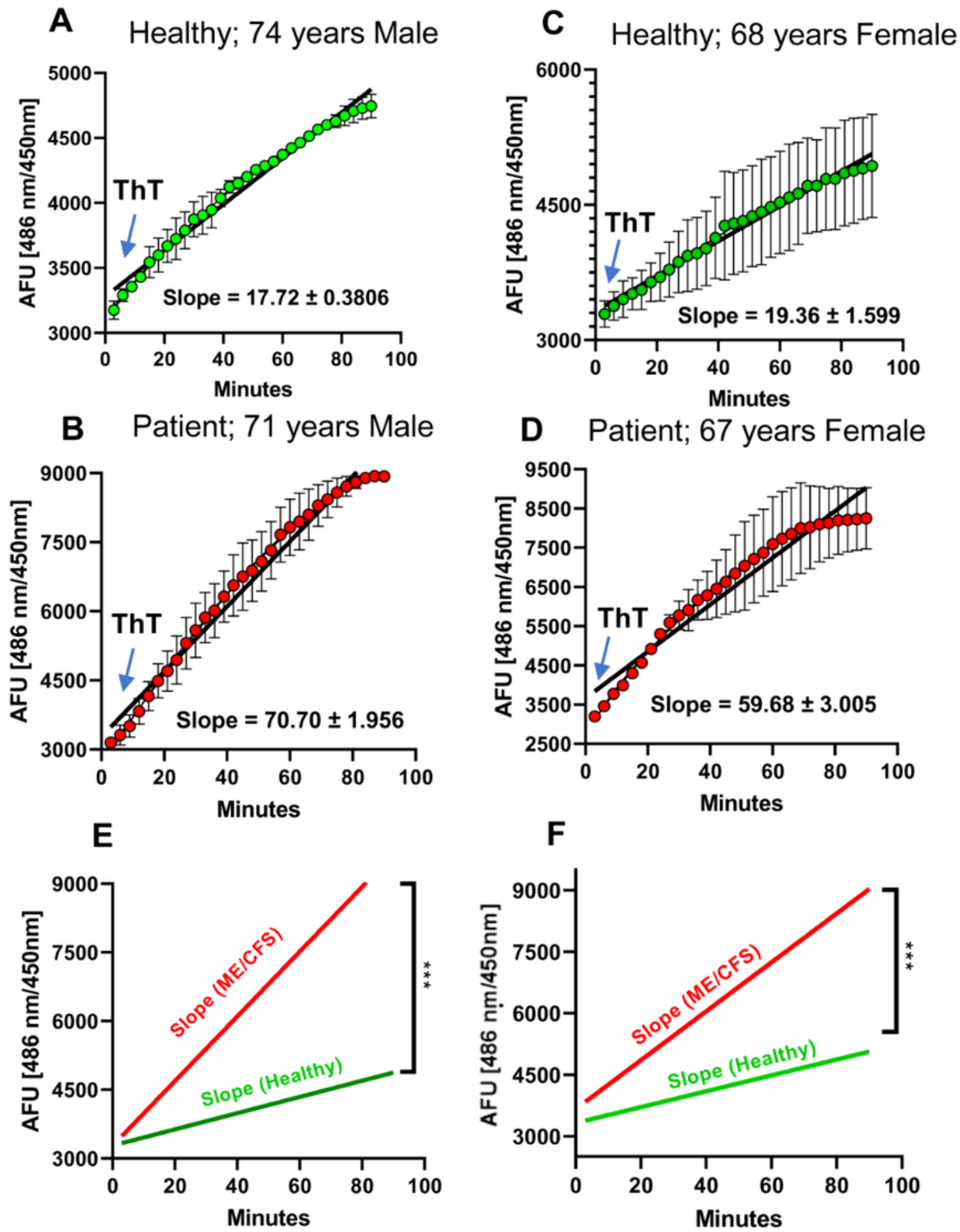

Fig.1

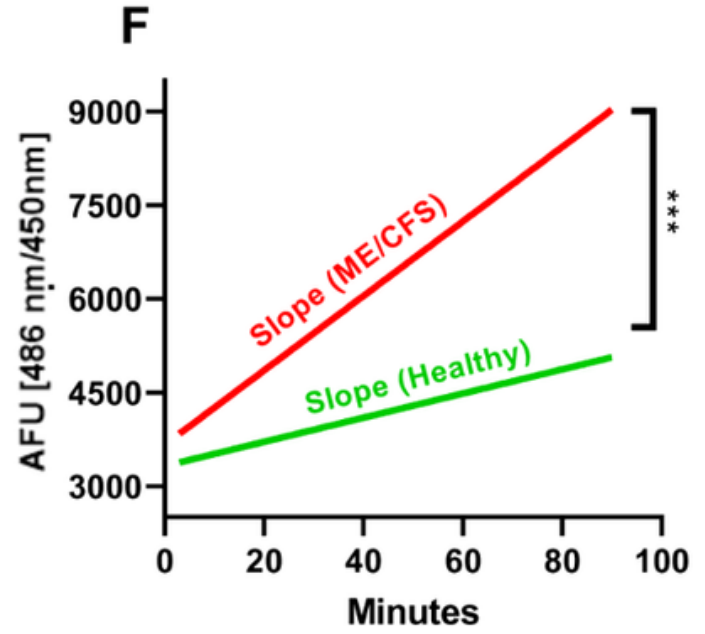

Figure 1

Thioflavin T assay to measure the protein aggregation tendency of serum proteins in ME/CFS patients. Two-hundred $\mu$ g protein containing serum samples of (A) 74 years old healthy male, (B) 71 years old Loading [MathJax]/jax/output/CommonHTML/fonts/TeX/fontdata.js d (D) 67 years old ME/CFS female were 
assayed for a Thioflavin T(ThT)-based protein aggregation assay. ThT Fluorescence absorbance [486/450 nm] was measured from 0 to 90 mins at 3 minutes of interval after ThT addition through autoinjector. Results are mean \pm SD of three independent experiments. (E \&F) Comparison of slope values between healthy controls (green) and patients (red). (E) represents liner slope value difference between 74 years healthy (green) and 71 years ME/CFS (red) males, whereas (F) represents the slope difference between 68 years healthy (green) and 67 years old ME/CFS females suggesting that ME/CFS patients might have potential abnormality in clearance of proteinopathic aggregates.

$$
\text { A }
$$

Healthy; 74 years Male

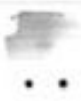

B

Patient; 71 years Male
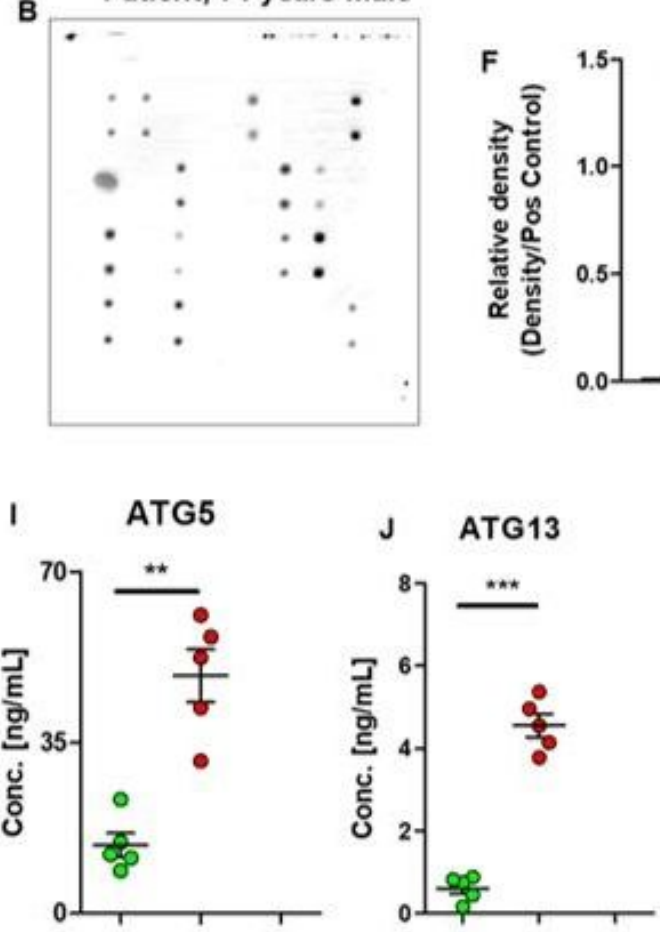

Fig. 2
ATG5

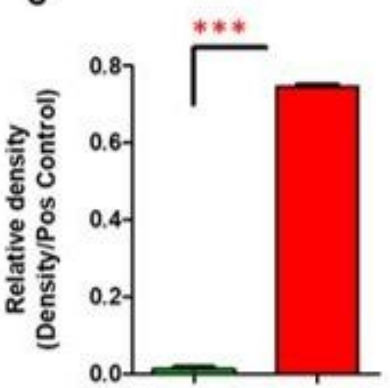

p62
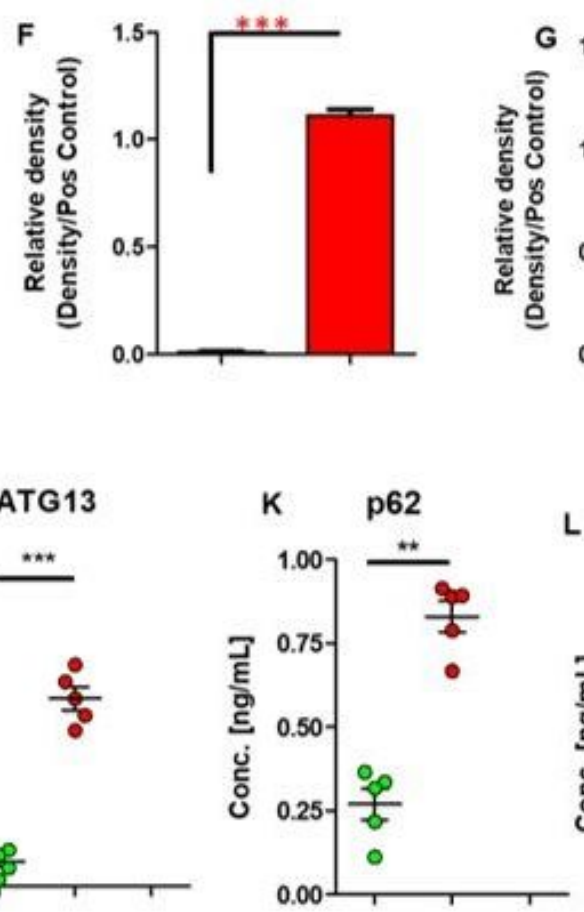

ATG7

D
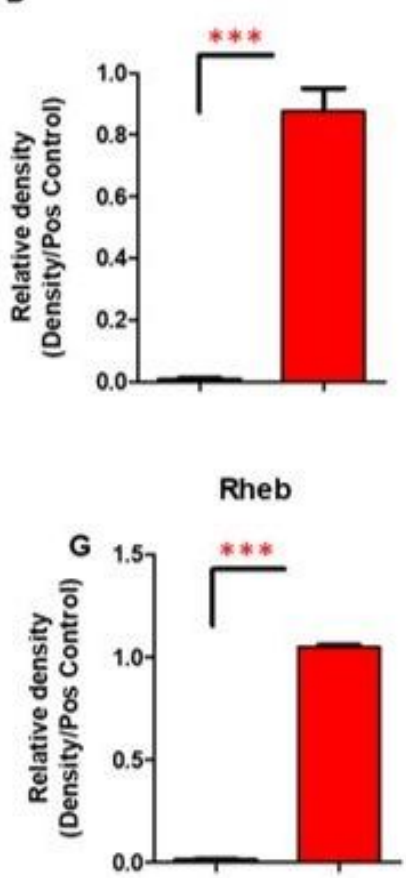

E
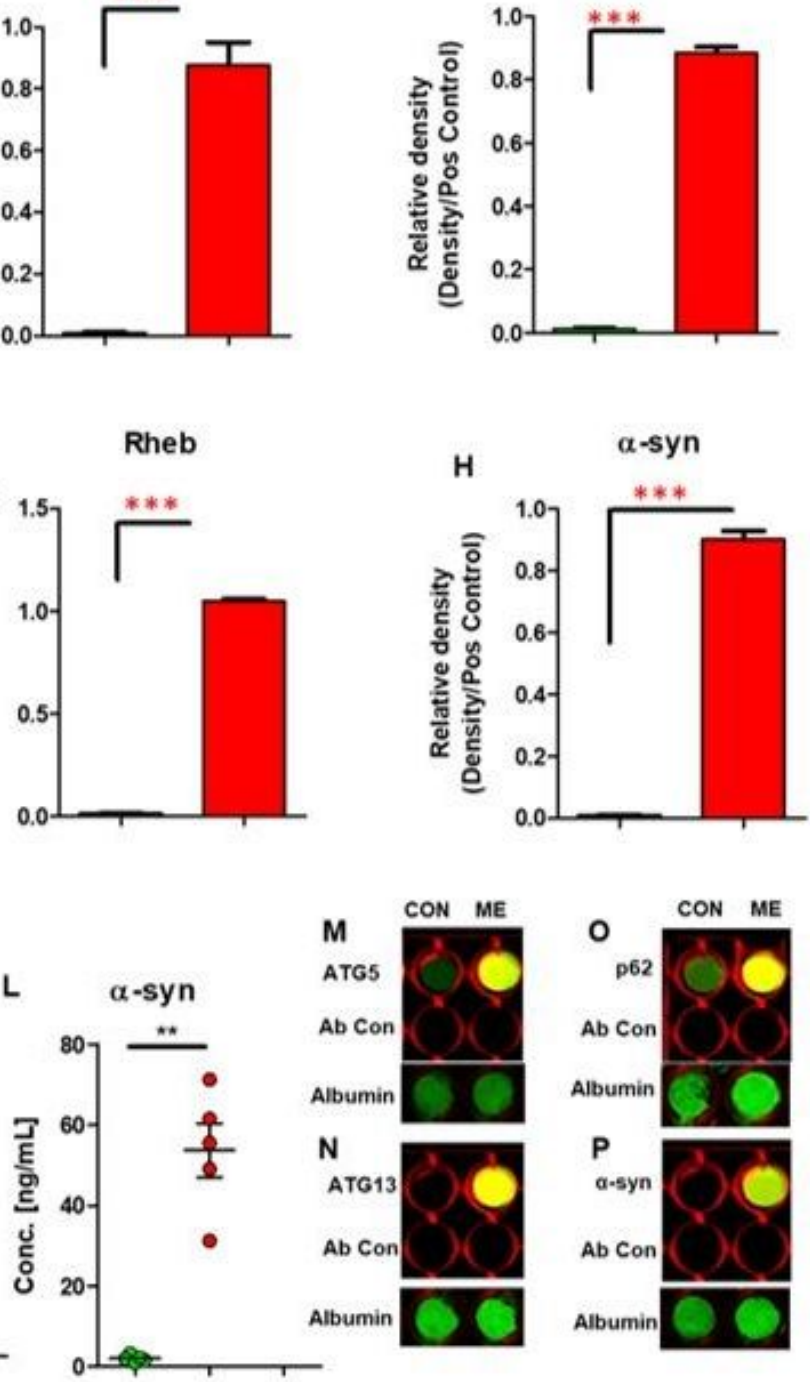

Figure 2

Case study I: Upregulations of Autophagy Markers in Serum of 71 years old ME/CFS patient. Serum samples of (A) 74 years old healthy male and (B) 71 years old male patient were assayed for an antibody array of autophagy biomarkers (RayBiotech; Cat \# AAH-ATG-1-4). (C-H) Densitometric analyses display strong upregulations of autophagic markers. Dot intensities of (C) ATG5 [***p<0.005(=0.000472)], (D) 
Rheb $[\star \star \star p<0.005(=0.00334)]$, and $(H) \alpha-$ syn $[\star \star \star p<0.005(=0.00172)]$ were measured in Image J software $(\mathrm{NIH}, \mathrm{USA})$ after subtraction with blank followed by normalization with positive control. Results were mean $\pm S D$ and confirmed after three independent experiments. ELISA analyses of (I) ATG5, (J) ATG13, (K) p62, and (L) a-syn were performed in healthy (green) and patient (red). Results were confirmed and considered to be significant after 5 independent experiments and indicated with 5 dots in a dotted histogram. Near -infrared ELISA assay for (M) ATG5, (N) ATG13, (0) p62, (P) a-syn. A paired t-test was done to assess the significance of mean. Antibody control was assessed without sample addition and then probing each well with only $2^{\circ}$ antibody. Albumin was run for both samples as a loading control.

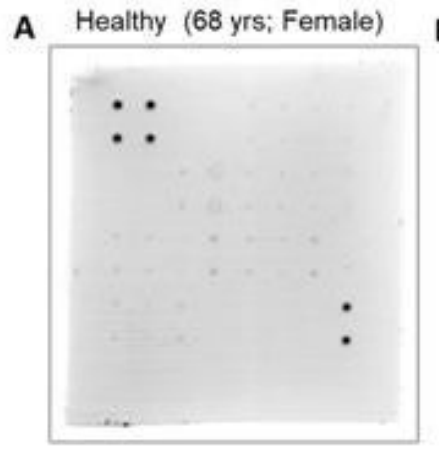

E
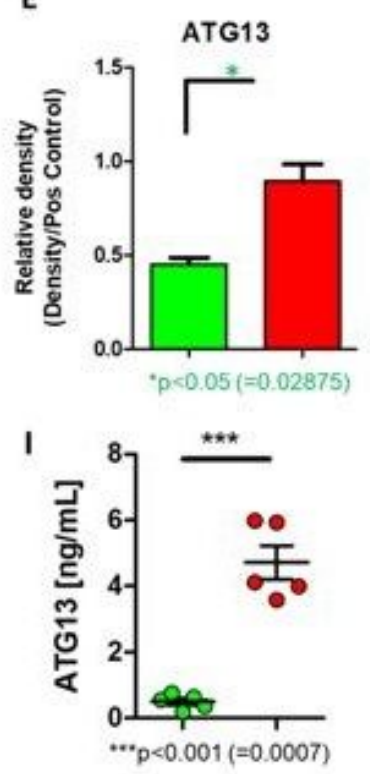

Fig. 3
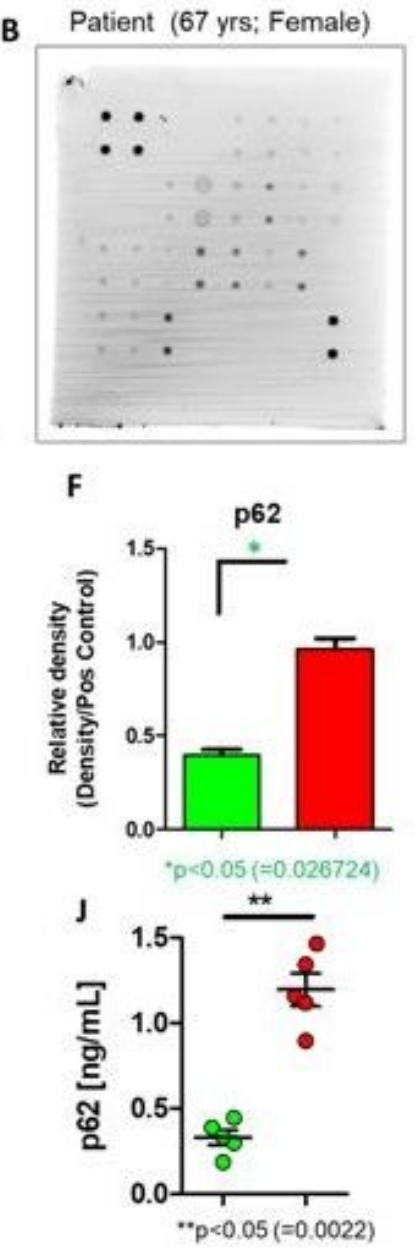
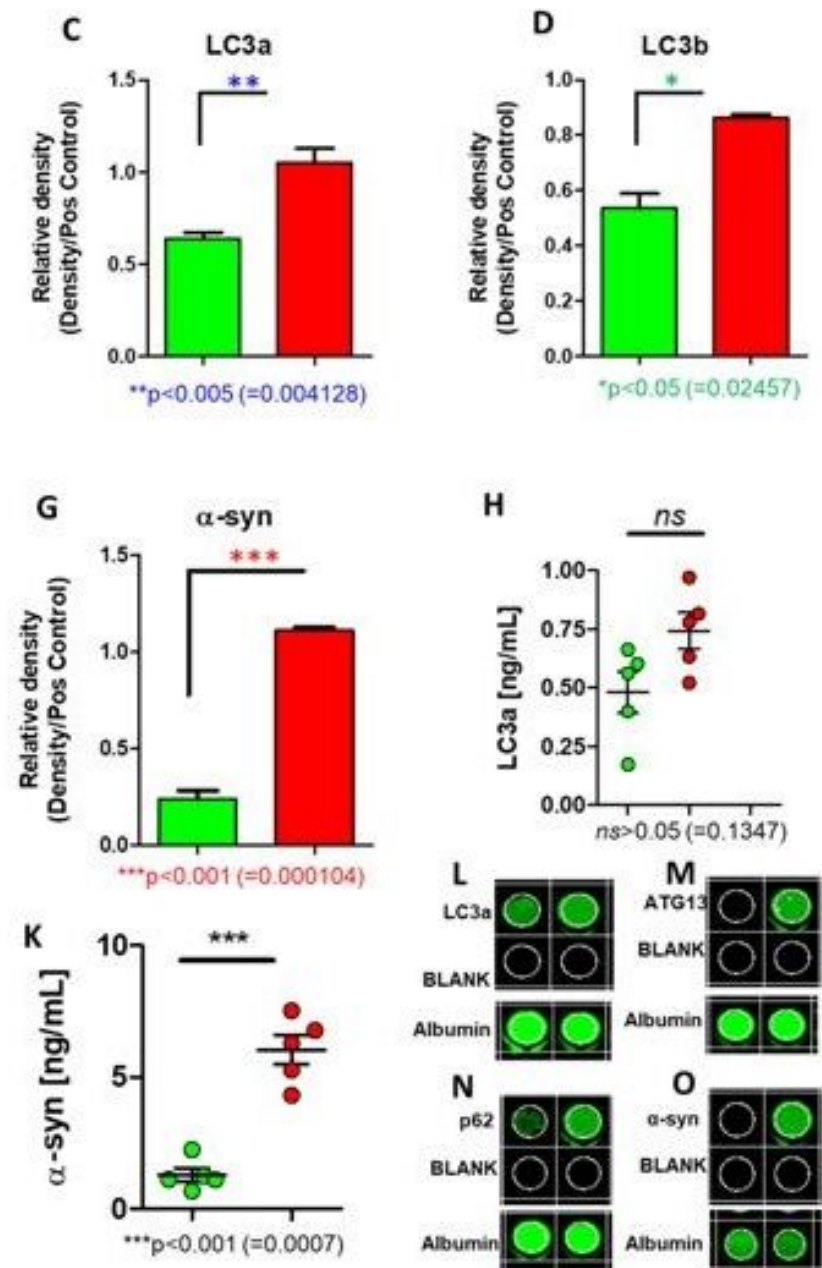

H
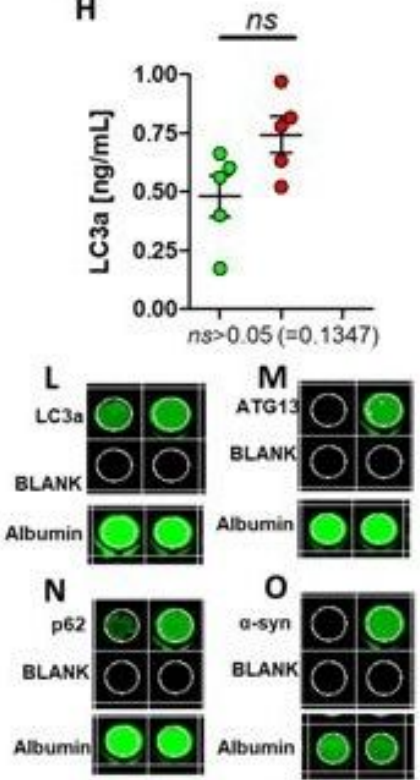

\section{Figure 3}

Case study II: Upregulations of Autophagy Markers in serum samples of 67 years old ME/CFS patient. Antibody array of 20 autophagy markers in serum samples of (A) healthy (68 years; female) and (B) patient (67 years; female). Densitometric analyses of (C) LC3a, (D) LC3b, (E) ATG13, (F) p62, and (G) asyn. Signal intensities were measured in ImageJ software, subtracted from blank, normalized with positive control, and then plotted as a histogram in GraphPad Prism 8 software. Results are mean \pm SD 
underneath. Quantitative ELISA analyses for (I) ATG13, (J) p62, and (K) a-syn were performed in serum samples of healthy (green) and patient (red). Result was confirmed after 5 independent experiments. Significance of mean was tested with paired t-test. Respective $p$ value was given below each dotted histogram. Near-infrared ELISA analyses for (L) LC3a, (M) ATG13, (N) p62, and (O) a-syn.
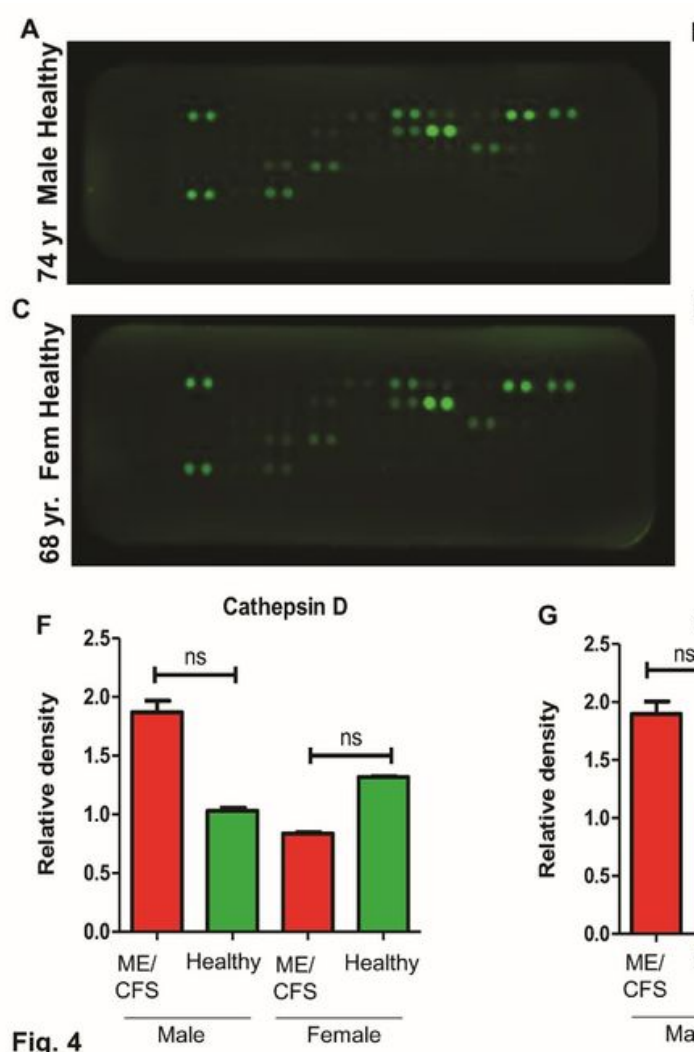

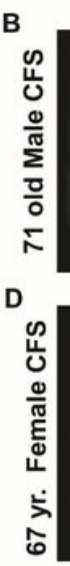

G

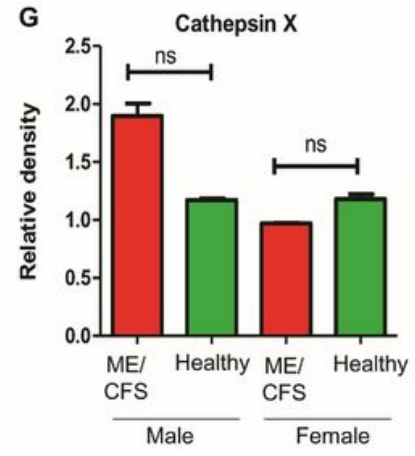

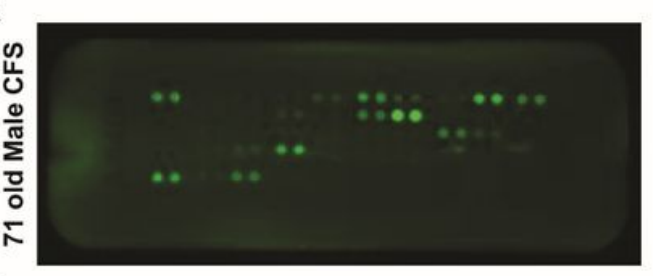
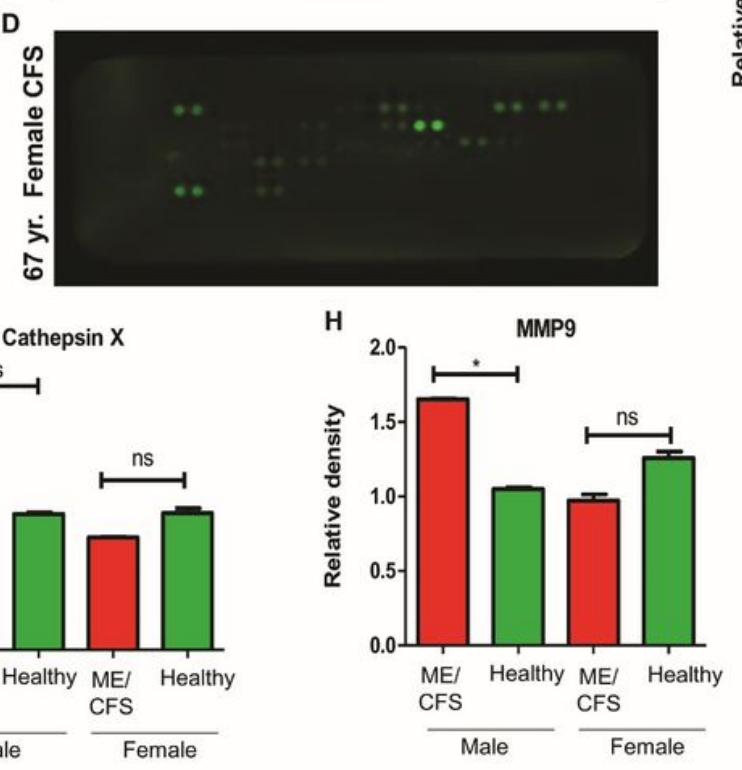

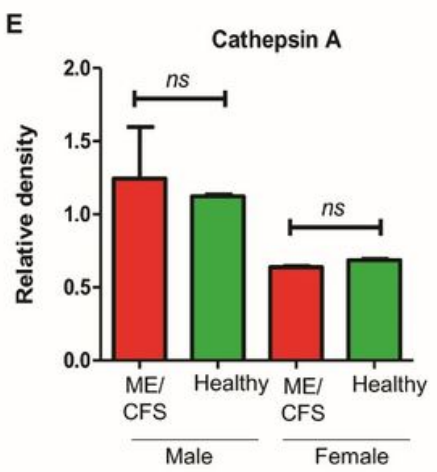

I

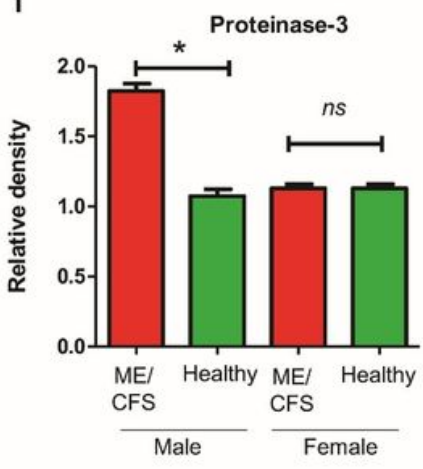

\section{Figure 4}

Levels of lysosomal and extra-lysosomal proteases in serum samples of two case-control subjects. Serum samples were diluted 1:5 ( $/ / \mathrm{v})$ with assay diluent and then probed against 34 different proteases in a human protease profiler array (R\& D systems; Cat \# ARY021) membrane. Array analyses were performed in serum samples of (A) healthy male, (B) male ME/CFS, (C) healthy female, and (D) female ME/CFS subjects. Relative densities of (E) cathepsin A, (F) cathepsin D, (G) cathepsin X, (H) MMP-9 and (I) proteinase-3 were calculated with respect to reference points and then plotted. Results were mean \pm SD of three independent experiments. Significance of mean was tested with unpaired t-test with * ${ }^{*}<0.05$. 

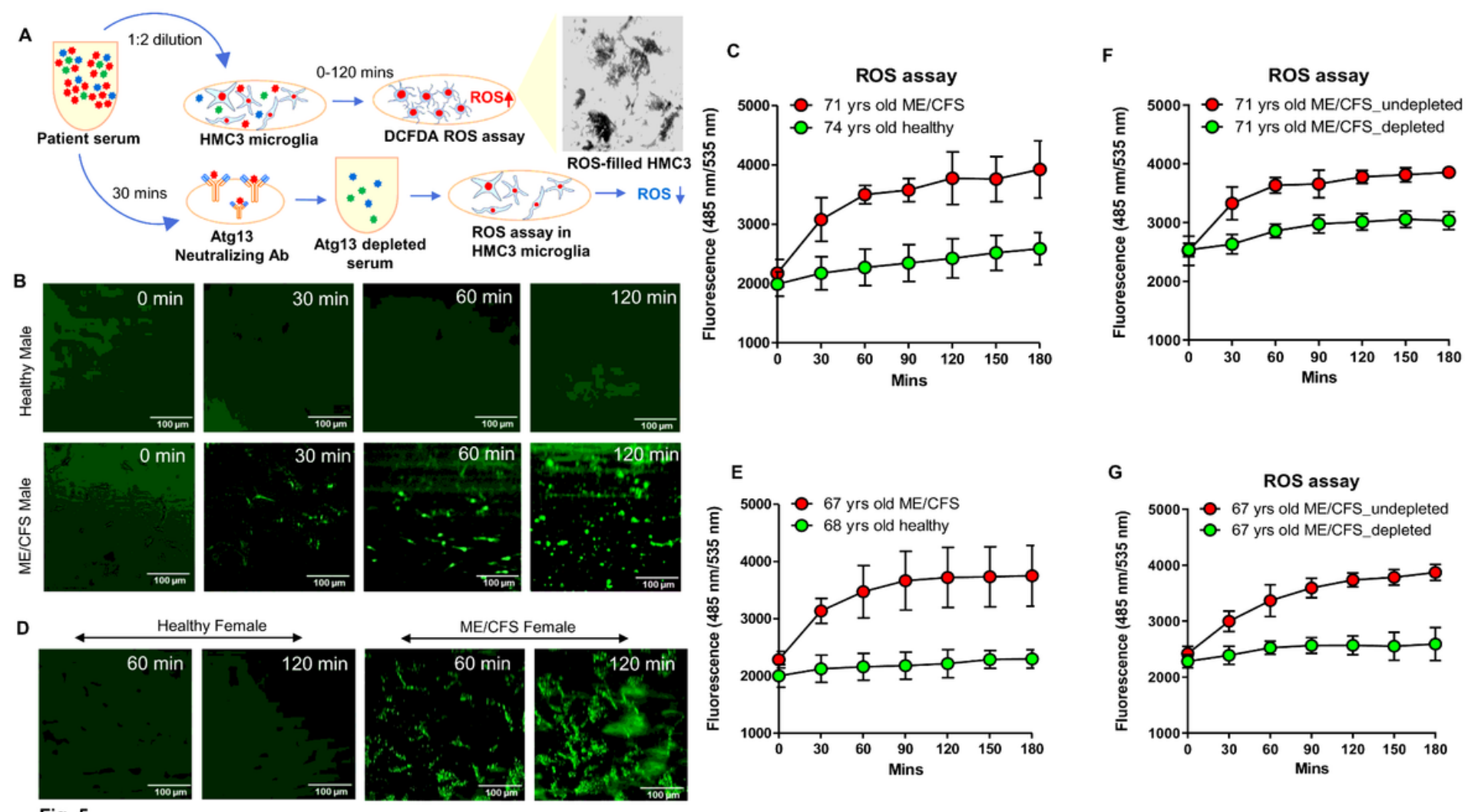

Fig. 5

Figure 5

Serum-derived ATG13 in ME/CFS patients evoked oxidative stress response in microglial cells. (A) A schema of overall experimental plan. (B) HMC3 human microglial cells were treated with ME/CFS patient's serum (1:2 diln) supplemented DMEM media for 0 min, 30 mins, 60 mins, and 120 mins. The ROS production was assayed with DCFDA staining procedure. (C) Realtime ROS production was assayed in HMC3 microglia after stimulation with male healthy (green) and ME/CFS (red) subjects. A timesensitive recording was performed at VictorX3 multichannel plate reader using $485 \mathrm{~nm} / 535 \mathrm{~nm}$ wavelength (Ex/Em) protocol. A time-dependent ROS production assay was recorded at $485 \mathrm{~nm} / 535 \mathrm{~nm}$ (Ex/Em) wavelength (D) HMC3 microglial cells were stimulated with sera (1:2 diln) of female healthy and ME/CFS patient for 60 and 120 mins followed by probing with DCFDA. Images were captured in FITCfilter of Hund fluorescence microscope. (E) Realtime ROS production was assayed at different time interval in HMC3 microglial cells once stimulated with sera of female healthy (green) and ME/CFS (red) subjects. (F) Similar ROS assay was performed in HMC3 cells after stimulation with the serum of male ME/CFS patient (red) and ATG13-depleted serum (green). (G) Similar ROS assay was performed in presence of female ME/CFS serum and ATG13-depleted serum. Result was mean \pm SD of three independent experiments. 

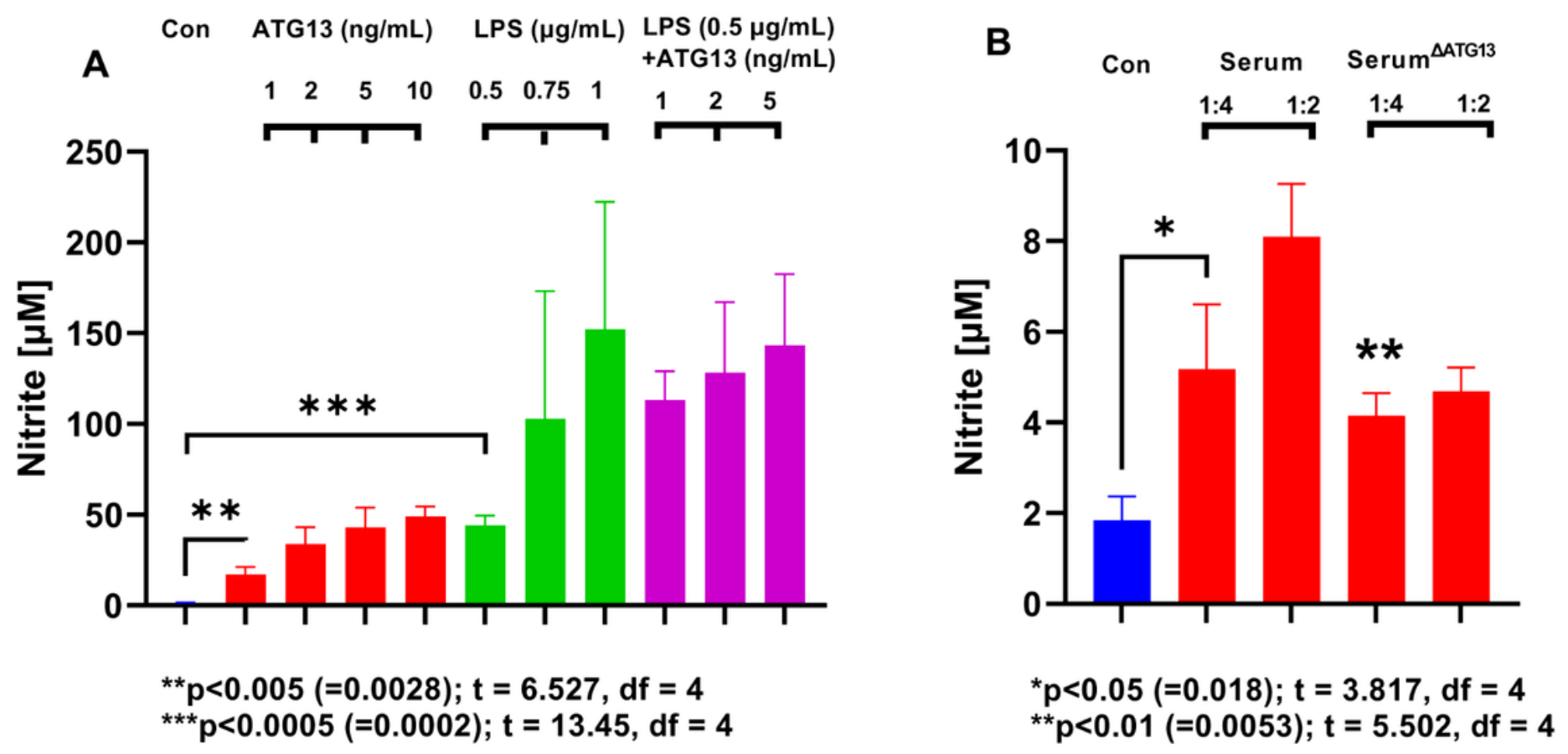

Fig. 6

Figure 6

Effect of serum-derived ATG13 on the production of nitric oxide (nitrite) in HMC3 microglial cells. (A) HMC3 microglial cells were stimulated with recombinant ATG13 proteins $(1-10 \mathrm{ng} / \mathrm{mL})$, LPS $(0.5-1$ $\mu \mathrm{g} / \mathrm{mL})$, and ATG13 $(1-5 \mathrm{ng} / \mathrm{mL})+$ LPS $(0.5 \mu \mathrm{g} / \mathrm{mL})$ under serum free condition for $24 \mathrm{hrs}$. After that, colorimetric Griess reaction was performed in supernatant and OD was measured at $575 \mathrm{~nm}$. (B) Serum sample of 71-year old male ME/CFS patient was neutralized with ATG13 and applied on HMC3 microglia at 1:2 and 1:4 dilution (diluted with serum-free DMEM media) for $24 \mathrm{hrs}$. After $24 \mathrm{hrs}$ nitric oxide production was measured by Griess method. The effect was compared with equivalent dilutions of serum without ATG13 neutralization. Results are mean \pm SD of three independent experiments. Significance of mean was tested with unpaired t-test and resultant $p$ values were presented underneath. 
A

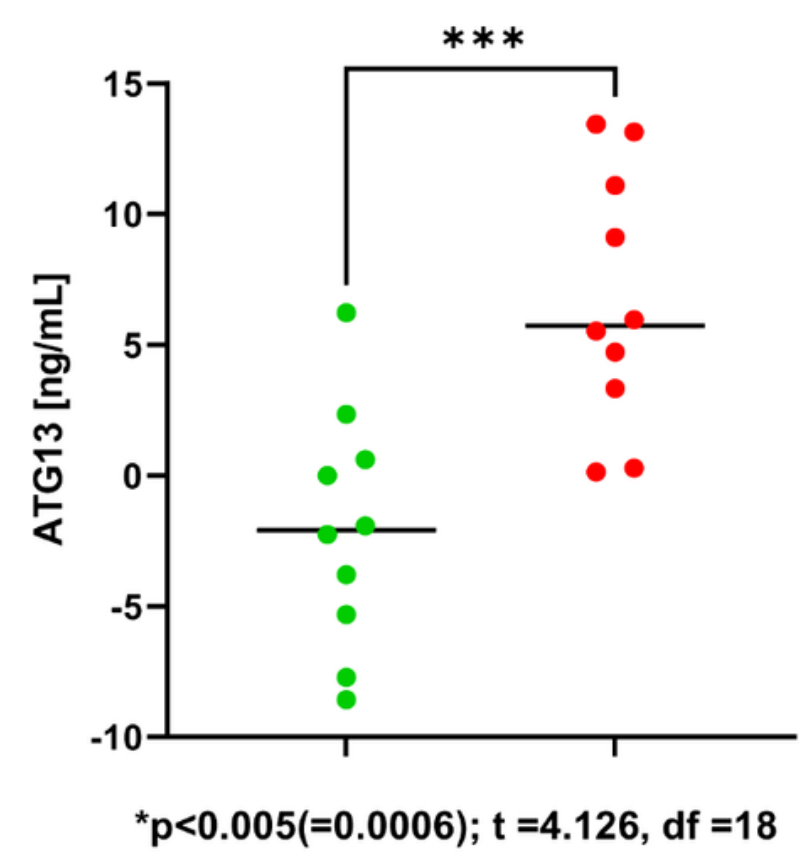

C

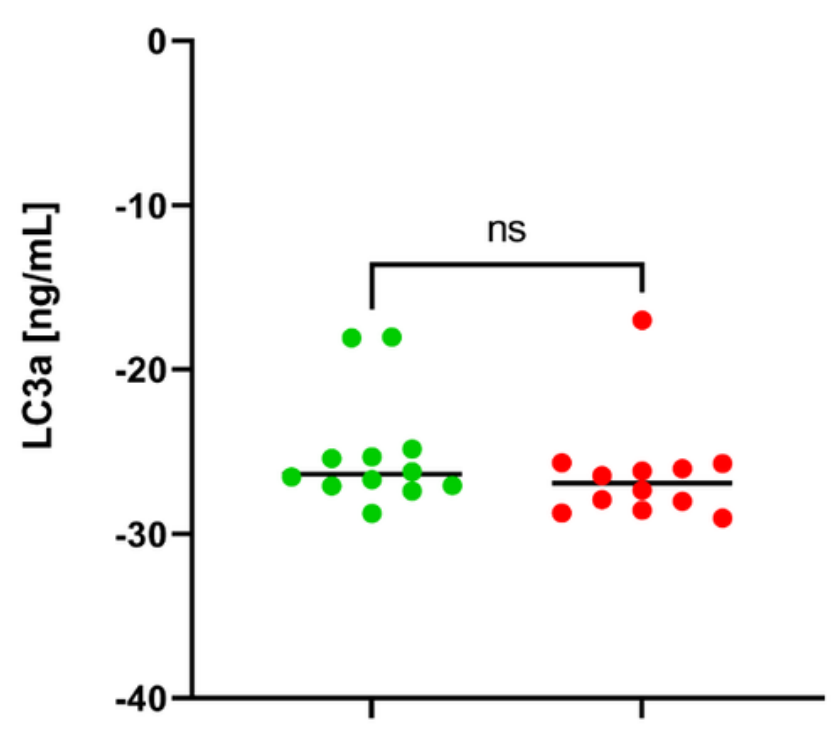

${ }^{n s} p>0.05(=0.3597) ; t=0.9354, d f=22$
B

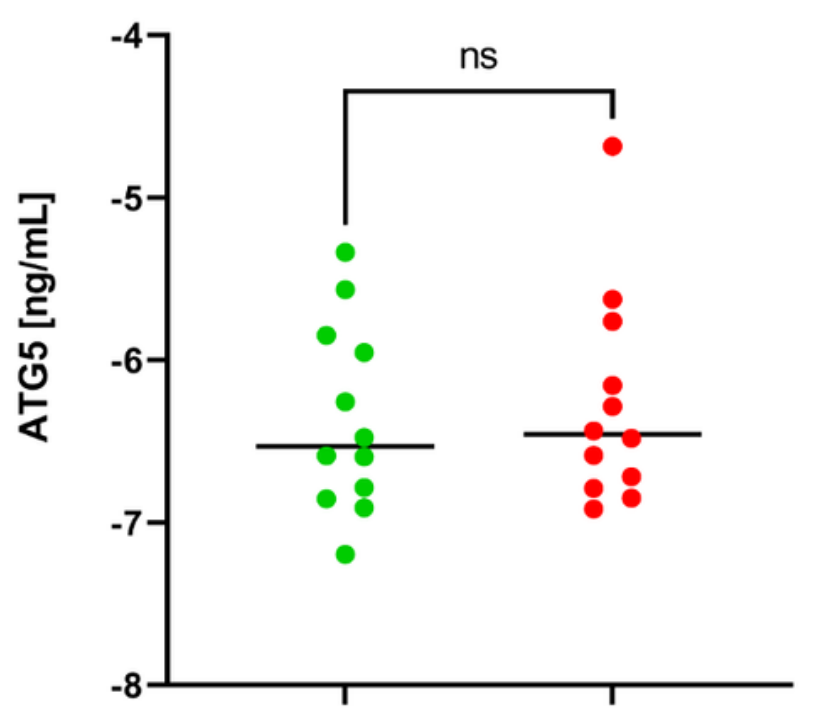

${ }^{n s} p>0.05(=0.7225) ; t=0.3597, d f=22$

D

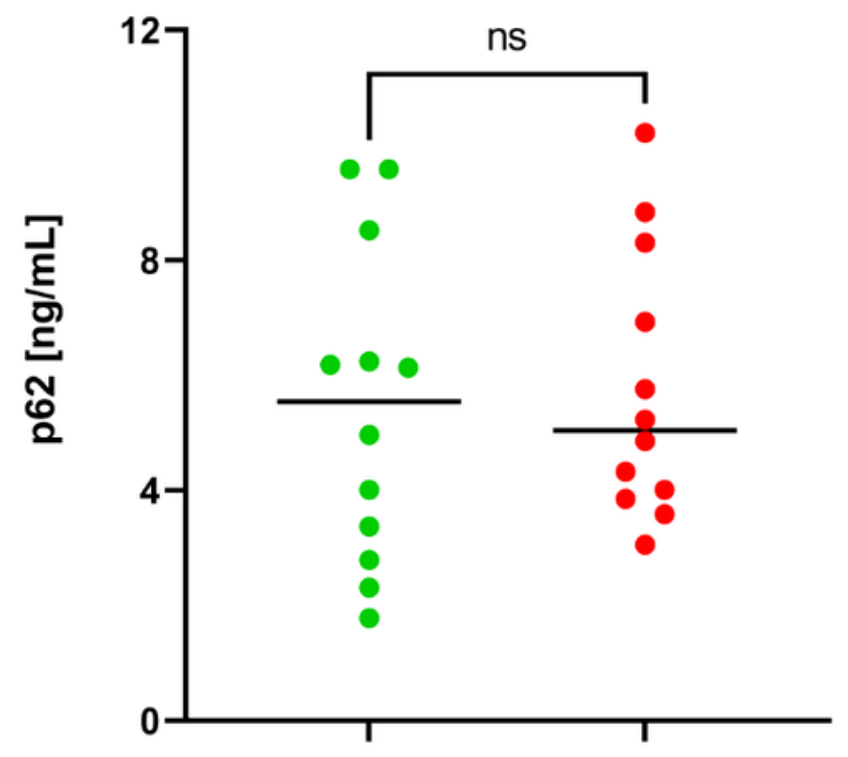

${ }^{n s} p>0.05(=0.7805) ; t=0.2821, \mathrm{df}=22$

Fig. 7

Figure 7

Analyzing expressions of ATG13, ATG5, LC3a, and p62 in a cohort of 10 ME/CFS and 10 healthy serum samples. A cohort of 10 healthy controls and $10 \mathrm{ME} / \mathrm{CFS}$ patients were analyzed for the expressions of (A) ATG13, (B) ATG5, (C) LC3a, and (D) p62 in serum samples. Results are mean \pm SD of three independent experiments. Significance of mean was tested with unpaired t-test and resultant $p$ values 


\section{Supplementary Files}

This is a list of supplementary files associated with this preprint. Click to download.

- ATG13PAPERSUPPLEMENTARYDOC.docx 